Article

\title{
Evaluating the Sensitivity of the Mass-Based Particle Removal Calculations for HVAC Filters in ISO 16890 to Assumptions for Aerosol Distributions
}

\author{
Brent Stephens 10 \\ Department of Civil, Architectural, and Environmental Engineering, Illinois Institute of Technology, Chicago, \\ IL 60616, USA; brent@iit.edu; Tel.: +1-312-567-3356
}

Received: 25 January 2018; Accepted: 23 February 2018; Published: 26 February 2018

\begin{abstract}
High efficiency particle air filters are increasingly being recommended for use in heating, ventilating, and air-conditioning (HVAC) systems to improve indoor air quality (IAQ). ISO Standard 16890-2016 provides a methodology for approximating mass-based particle removal efficiencies for $\mathrm{PM}_{1}, \mathrm{PM}_{2.5}$, and $\mathrm{PM}_{10}$ using size-resolved removal efficiency measurements for $0.3 \mu \mathrm{m}$ to $10 \mu \mathrm{m}$ particles. Two historical volume distribution functions for ambient aerosol distributions are assumed to represent ambient air in urban and rural areas globally. The goals of this work are to: (i) review the ambient aerosol distributions used in ISO 16890, (ii) evaluate the sensitivity of the mass-based removal efficiency calculation procedures described in ISO 16890 to various assumptions that are related to indoor and outdoor aerosol distributions, and (iii) recommend several modifications to the standard that can yield more realistic estimates of mass-based removal efficiencies for HVAC filters, and thus provide a more realistic representation of a greater number of building scenarios. The results demonstrate that knowing the PM mass removal efficiency estimated using ISO 16890 is not sufficient to predict the PM mass removal efficiency in all of the environments in which the filter might be used. The main reason for this insufficiency is that the assumptions for aerosol number and volume distributions can substantially impact the results, albeit with some exceptions.
\end{abstract}

Keywords: particulate matter; indoor air quality; filtration; $\mathrm{PM}_{2.5} ; \mathrm{PM}_{10} ; \mathrm{ISO} 16890$; MERV

\section{Introduction}

High efficiency particle air filters are increasingly being recommended for use in heating, ventilating, and air-conditioning (HVAC) systems to improve indoor air quality (IAQ) by controlling indoor particulate matter (PM) from both indoor and outdoor sources [1-7]. The two most widely used global test standards for evaluating HVAC filters, ASHRAE Standard 52.2-2017 [8] and ISO Standard 16890-2016 [9], describe procedures to experimentally characterize the single-pass particle removal efficiency of filters in laboratory settings. Both standards require measurements of size-resolved particle removal efficiency under various loading conditions for particles that are $0.3 \mu \mathrm{m}$ to $10 \mu \mathrm{m}$ in size.

ASHRAE Standard 52.2 uses the resulting size-resolved removal efficiency data to classify average filter efficiency in three aggregate particle size bins within the measured range (i.e., $0.3-1 \mu \mathrm{m}, 1-3 \mu \mathrm{m}$, and 3-10 $\mu \mathrm{m}$ ). Removal efficiencies in the three size bins are then used to assign HVAC filters a single efficiency metric, which is the minimum efficiency reporting value (MERV), and is based on the minimum removal efficiency in each of the three bins. Although the vast majority of the epidemiological evidence of adverse health outcomes that are associated with airborne particulate matter to date has been linked to mass-based concentrations of $\mathrm{PM}_{1}, \mathrm{PM}_{2.5}$, and $\mathrm{PM}_{10}$ [10-20], the ASHRAE Standard 52.2 test method does not explicitly evaluate particle removal efficiency for any of these mass-based measures. 
Conversely, the ISO 16890 series of standards, which have now replaced the predecessor EN 779 standard [21], also uses the resulting size-resolved efficiency data from lab testing for the same $0.3 \mu \mathrm{m}$ to $10 \mu \mathrm{m}$ size range to approximate mass-based particle removal efficiencies for three size classifications that are commonly used in ambient regulatory monitoring and building measurements: $e \mathrm{PM}_{1}, e \mathrm{PM}_{2.5}$, and $e \mathrm{PM}_{10}$ for the mass of particles smaller than $1 \mu \mathrm{m}, 2.5 \mu \mathrm{m}$, and $10 \mu \mathrm{m}$, respectively. The method described in ISO 16890 calculates $e \mathrm{PM}_{1}, e \mathrm{PM}_{2.5}$, and $e \mathrm{PM}_{10}$ according to the following procedures. It is assumed that removal efficiency measurements from the following particle size bins are used for each $e \mathrm{PM}$ category: $0.3-1 \mu \mathrm{m}$ for $e \mathrm{PM}_{1}, 0.3-2.5 \mu \mathrm{m}$ for $e \mathrm{PM}_{2.5}$, and 0.3-10 $\mu \mathrm{m}$ for $e \mathrm{PM}_{10}$. Two historical bimodal volume distribution functions for ambient aerosol distributions are assumed to represent ambient air in urban and rural areas globally. The use of volume distributions necessitates an underlying assumption of spherical particles and constant unit density for volume-based removal efficiencies that yields an equivalent to mass-based removal efficiencies. While these assumptions are not always valid [22-24], they are widely used assumptions [25-28] that have been shown to have only a minimal impact on estimates of mass-based removal efficiency for HVAC filters [29]. Next, filters that are designed to filter primarily $\mathrm{PM}_{1}$ and $\mathrm{PM}_{2.5}$ size fractions are assumed to be characterized using the urban volume distribution function, while filters designed to filter primarily $\mathrm{PM}_{10}$ are assumed to be characterized using the rural volume distribution function. Finally, the average measured size-resolved fractional removal efficiencies in each relevant size bin for each size classification are used in conjunction with the assumed urban and rural ambient volume distributions to calculate $e \mathrm{PM}_{1}$, $e \mathrm{PM}_{2.5}$, and $e \mathrm{PM}_{10}$ for a given filter. This approach essentially involves calculating the volume/mass distribution that would exist downstream of a filter, and comparing that term to the original assumed volume/mass distribution that would exist upstream of the filter.

There are at least two potential issues with this approach to estimating mass-based removal efficiency in ISO 16890 that may lead to inaccurate or unrealistic estimates of $e \mathrm{PM}_{1}, e \mathrm{PM}_{2.5}$, and $e \mathrm{PM}_{10}$. First, the reliance on historical and static ambient aerosol distributions may not be representative of modern ambient aerosol distributions. Second, the reliance on ambient aerosol distributions alone, rather than indoor aerosol distributions that result from a combination of ambient infiltration and/or indoor sources, may limit the conditions under which the standard is applicable (i.e., only to $100 \%$ outdoor air HVAC systems, and not to recirculating HVAC systems or buildings relying on infiltration for the ventilation air, both of which are very prevalent in the United States (US) in particular). Therefore, the goals of this work are to: (i) review the ambient aerosol distributions used in ISO 16890, (ii) evaluate the sensitivity of the $e \mathrm{PM}$ calculation procedures described in ISO 16890 to assumptions for indoor and outdoor aerosol distributions, and (iii) recommend several modifications to the standard that can yield more realistic estimates of $e$ PM for HVAC filters for more realistic building scenarios.

\section{Methods}

A literature review was first conducted to explore the origin of the historical and static ambient aerosol distributions that have been used for calculating $e \mathrm{PM}$ in ISO 16890, and to identify more recent ambient and indoor aerosol distributions that could potentially be used instead. Estimates of $e \mathrm{PM}$ were then made for several HVAC filters using: (i) the historical distributions used in ISO 16890, (ii) the updated ambient aerosol distributions from the literature review, and (iii) a sample of indoor and ambient-infiltrated aerosol distributions obtained from the literature review.

The following procedures were used to estimate the $e \mathrm{PM}$ for each assumed volume distribution in this work. For each mode of a trimodal lognormal distribution, the size-dependent number concentration in each size bin $\left(d N_{i}\right)$ normalized for the logarithm of the bin width $\left(d \log d_{p}\right)$ was estimated using Equation (1) (Seinfeld and Pandis, 2006 [30]).

$$
\frac{d N_{i}}{d \log d_{p}}=\frac{N}{\log \sigma_{g} \sqrt{2 \pi}} e^{-\frac{\left(\log d_{p}-\log d_{g}\right)^{2}}{2\left(\log \sigma_{g}\right)^{2}}}
$$


where $N=$ the total number concentration in the mode $\left(\# / \mathrm{cm}^{3}\right) ; d_{p}=$ particle diameter (in increments of $\left.\log d_{p}=0.1\right)(\mu \mathrm{m}) ; d_{g}=$ geometric mean diameter for the mode $(\mu \mathrm{m})$; and $\sigma_{g}=$ geometric standard deviation for the mode (-). The sum total of $d N / d \log d_{p}$ for each particle size bin in the trimodal distribution was then calculated as the sum of $d N_{i} / d \log d_{p}$ from each of three modes.

Next, the size-dependent volume concentration in each size bin normalized for the logarithm of the bin width (i.e., $d V_{i} / d \log d_{p}$ ) was calculated for the trimodal distribution using Equation (2), assuming spherical particles.

$$
\frac{d V_{i}}{d \log d_{p}}=\frac{d N_{i}}{d \log d_{p}} \frac{\pi d_{p}^{3}}{6}
$$

The size-dependent volume distribution in each size bin $\left(d V_{i}\right)$ was then calculated by multiplying the bin width-normalized distribution (i.e., $d V_{i} / d \log d_{p}$ ) by the difference in the logarithms of the upper and lower bounds of each size bin (i.e., $d \log d_{p}$ ), as shown in Equation (3).

$$
d V_{i}=\frac{d V_{i}}{d \log d_{p}}\left(\log d_{p, \text { upper }}-\log d_{p, \text { lower }}\right)
$$

The mass concentrations of each of the three size classifications (i.e., $\mathrm{PM}_{1}, \mathrm{PM}_{2.5}$, and $\mathrm{PM}_{10}$ ) resulting from each distribution were then calculated using Equations (4)-(6), assuming constant unit density (i.e., $1 \mathrm{~g} / \mathrm{cm}^{3}$ ). One can consider these estimates to represent the "upstream" mass concentration that a filter would be challenged with based on the assumed aerosol distribution.

$$
\begin{aligned}
P M_{1, \text { upstream }} & =\sum_{i=0.3 \mu \mathrm{m}}^{1 \mu \mathrm{m}} d V_{i} \\
P M_{2.5, \text { upstream }} & =\sum_{i=0.3 \mu \mathrm{m}}^{2.5 \mu \mathrm{m}} d V_{i} \\
P M_{10, \text { upstream }} & =\sum_{i=0.3 \mu \mathrm{m}}^{10 \mu \mathrm{m}} d V_{i}
\end{aligned}
$$

The volume concentration "downstream" of a filter for each size bin (i.e., $d V_{i, \text { downstream }}$ ) was then calculated using Equation (7).

$$
d V_{i, \text { downstream }}=d V_{i}\left(1-\eta_{i}\right)
$$

where $\eta_{i}=$ the removal efficiency for a given filter for given particle size bin $i(-)$.

The mass concentration "downstream" of a filter for each of the three size classifications (i.e., $\mathrm{PM}_{1}$, $\mathrm{PM}_{2.5}$, and $\mathrm{PM}_{10}$ ) was then calculated using Equations (8)-(10), again assuming constant unit density.

$$
\begin{aligned}
P M_{1, \text { downstream }} & =\sum_{i=0.3 \mu \mathrm{m}}^{1 \mu \mathrm{m}} d V_{i, \text { downstream }} \\
P M_{2.5, \text { downstream }} & =\sum_{i=0.3 \mu \mathrm{m}}^{2.5 \mu \mathrm{m}} d V_{i, \text { downstream }} \\
P M_{10, \text { downstream }} & =\sum_{i=0.3 \mu \mathrm{m}}^{10 \mu \mathrm{m}} d V_{i, \text { downstream }}
\end{aligned}
$$


Finally, estimates of $e \mathrm{PM}_{1}, e \mathrm{PM}_{2.5}$, and $e \mathrm{PM}_{10}$ were made by dividing the "downstream" mass concentrations by the "upstream" mass concentrations for each of the three size classifications, and subtracting that term from unity, as shown in Equations (11)-(13).

$$
\begin{aligned}
e P M_{1} & =1-\frac{P M_{1, \text { downstream }}}{P M_{1, \text { upstream }}} \\
e P M_{2.5} & =1-\frac{P M_{2.5, \text { downstream }}}{P M_{2.5, \text { upstream }}} \\
e P M_{10} & =1-\frac{P M_{10, \text { downstream }}}{P M_{10, \text { upstream }}}
\end{aligned}
$$

\section{Results}

\subsection{Origin of the Historical Ambient Aerosol Distributions Used in ISO 16890}

The urban and rural volume distributions that are used in ISO 16890 were taken directly from one of the most widely regarded textbooks on atmospheric chemistry and physics: Seinfeld and Pandis (2006) [30]. The distributions are reported as trimodal distributions (shown in Figure 1 with summary statistics provided in Table 1), although ISO 16890 assumes they are bimodal distributions with lognormal parameter fits, which are described in Table 2 in part 1 of the standard (i.e., just the two larger modes, ignoring the smallest mode). This assumption is considered reasonable, because the standard does not require removal efficiency measurements below $0.3 \mu \mathrm{m}$. Interestingly, the aerosol distributions in Seinfeld and Pandis (2006) [30] are quite dated, and their original source is worth investigating further.
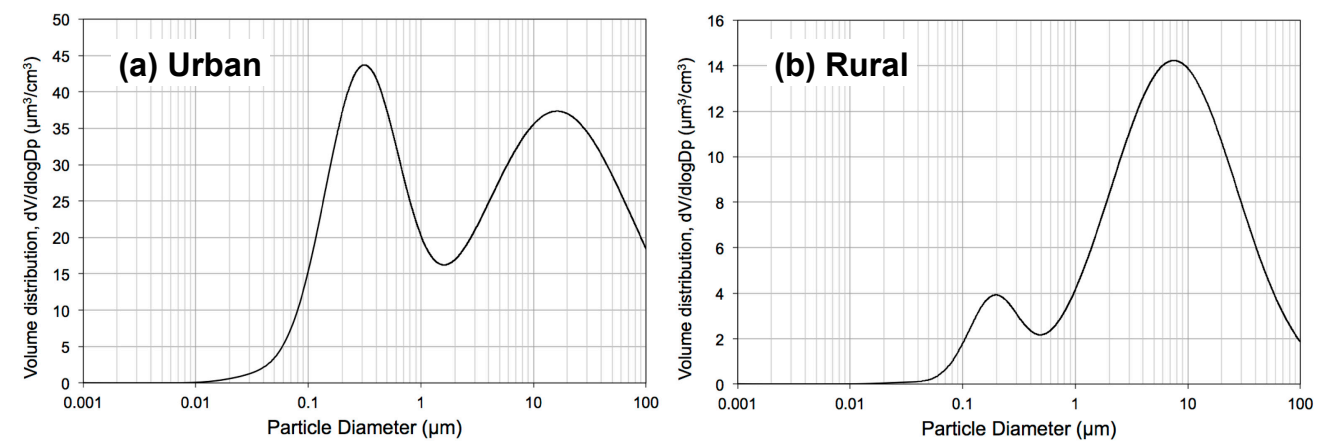

Figure 1. Volume distribution functions recreated from the trimodal (a) urban and (b) rural ambient aerosol distributions reported in Seinfeld and Pandis (2006) [30] and Jaenicke (1993) [31].

Table 1. Total number concentrations, geometric mean diameters, and geometric standard deviations for the trimodal ambient aerosol distributions from Jaenicke (1993) [31] and used in ISO 18690 [9].

\begin{tabular}{cccccccccc}
\hline \multirow{2}{*}{ Distribution } & \multicolumn{3}{c}{ Mode 1 } & \multicolumn{3}{c}{ Mode 2 } & \multicolumn{3}{c}{ Mode 3 } \\
\cline { 2 - 10 } & $N\left(\# / \mathrm{cm}^{3}\right)$ & $D_{g}(\mu \mathrm{m})$ & $\log \sigma_{g}$ & $N\left(\# / \mathrm{cm}^{3}\right)$ & $D_{g}(\mu \mathrm{m})$ & $\log \sigma_{g}$ & $N\left(\# / \mathrm{cm}^{3}\right)$ & $D_{g}(\mu \mathrm{m})$ & $\log \sigma_{g}$ \\
\hline Urban & $9.93 \times 10^{4}$ & 0.013 & 0.245 & $1.1 \times 10^{3}$ & 0.014 & 0.666 & $3.64 \times 10^{4}$ & 0.050 & 0.337 \\
Rural & 6650 & 0.015 & 0.225 & 147 & 0.054 & 0.557 & 1990 & 0.084 & 0.266 \\
\hline
\end{tabular}

Seinfeld and Pandis (2006) [30] reference the urban and rural distributions to Jaenicke (1993) [31], who summarized prototypical aerosol distributions for various ambient environments. Jaenicke's work has been widely used in other indoor environmental research and applications, including in a widely cited study on the size-resolved dynamics of outdoor aerosol transport and persistence in buildings [25]. Following the literature further, Jaenicke (1993) [31] appears to have gathered these 
aerosol distribution data from publications dating as far back as the 1970s. Specifically, the rural aerosol distributions reported in Jaenicke (1993) [31] are stated to come from measurements in the lower troposphere over the high plains of North America that were conducted in 1975 and 1976 using a combination of electrical aerosol analyzer (EAA: $\sim 0.01-0.36 \mu \mathrm{m}$ ), optical particle counter (OPC: $\sim 0.3-40 \mu \mathrm{m}$ ), and an axially scattering spectrometer (ASSP: $\sim 1.4-45 \mu \mathrm{m}$ ) [32]. The urban aerosol distributions reported in Jaenicke (1993) [31] appear to come from two publications from the 1960s and 1970s that used the same combination of aerosol monitoring equipment [33,34], although it is not immediately clear exactly what was the original source of the urban aerosol data. Regardless, the reliance on static assumptions for historical ambient aerosol distributions from the 1970s or earlier raises questions about the relevance and validity of using the distributions to estimate realistic values for $e \mathrm{PM}_{1}, e \mathrm{PM}_{2.5}$, and $e \mathrm{PM}_{10}$ today, which this work attempts to address.

\subsection{How Relevant Are the Historical Ambient Aerosol Distributions Used in ISO 16890 Today?}

One of the largest known reviews of ambient aerosol distributions globally is Azimi et al. (2014) [29], which identified a total of 194 long-term average ambient distributions (i.e., from one year or more of measurements) primarily from North America (i.e., the US and Canada) and Europe (i.e., Sweden, Finland, Norway, Denmark, Germany, France, Italy, Ireland, England, Netherlands, Switzerland, Lithuania, Hungary, the Czech Republic, and Bulgaria). The article fit trimodal lognormal distributions to each of the 194 distributions found in the literature, and reported geometric means, geometric standard deviations, and total number concentrations for each mode fit. The article also estimated $\mathrm{PM}_{2.5}$ concentrations for each distribution, assuming spherical particles and both unit and varying size-dependent density.

Azimi et al. (2014) [29] also used the 194 ambient distributions to estimate the fractional removal efficiencies for a number of HVAC filters for integral measures of $\mathrm{PM}_{2.5}$ and total ultrafine particles (i.e., UFPs: all particles smaller than $100 \mathrm{~nm}$ ). The work followed a similar procedure as that described in ISO 16890 and in Section 2 herein, albeit with the following exceptions: (1) 194 long-term average trimodal ambient aerosol distributions from around the world were used, rather than a single static urban or rural bimodal distribution; (2) fractional filter removal efficiency data from laboratory tests that measured down to as small as $30 \mathrm{~nm}$ were used (and the remaining data were fit with a model down to just a few nanometers) [35]; and (3) in addition to estimating $\mathrm{PM}_{2.5}$ and UFP removal efficiencies assuming $100 \%$ outdoor air delivery, $\mathrm{PM}_{2.5}$ and UFP removal efficiencies for indoor particles of outdoor origin were also estimated assuming ambient aerosols penetrated through the building envelope of a typical residential building with a recirculating HVAC system. This approach allowed for estimates of the $\mathrm{PM}_{2.5}$ and UFP removal efficiency for various filters for indoor particles of outdoor origin, which is a condition that frequently occurs in many buildings when indoor sources are not present [36-40]. The number and volume distributions from the 194 outdoor particle size distributions reviewed in Azimi et al. (2014) [29] are shown in Figure 2, with the number and volume distributions from Jaenicke (1993) [31] overlaid.

Although the ambient number concentrations in Jaenicke (1993) [31] are clearly much higher in magnitude than all 194 of the more recent ambient distributions, largely due to decreasing historical trends in ambient particulate matter concentrations over time, the shape of the number distributions still share some similarities. For example, they all have a peak number concentration around $10-20 \mathrm{~nm}$. However, there are also some deviations between the two sets of distributions, particularly around 0.05-0.5 $\mu \mathrm{m}$. Conversely, the volume distributions from Jaenicke (1993) [31] appear to be very different from the other distributions from the recent literature. However, the main reason for the differences in the volume distributions, particularly in the $>2.5 \mu \mathrm{m}$ size range, is the use of different aerosol monitoring instruments in each study. Most recent measurements have been made using a scanning mobility particle sizer (SMPS) with an upper size limit for the number concentrations of as high as $\sim 0.8 \mu \mathrm{m}$, while only a few also used an optical particle sizer (OPS, with an upper size limit of $\sim 10 \mu \mathrm{m}$ ) or an aerodynamic particle sizer (APS, with an upper size limit of $\sim 20 \mu \mathrm{m}$ ). The combination of 
instruments used to measure the distributions reported in Jaenicke (1993) [31] (i.e., EAA and OPC) yielded substantial coverage of number concentrations above $1 \mu \mathrm{m}$, and thus the results could be used to accurately identify the large volume peaks in the $\sim 5-20 \mu \mathrm{m}$ size range. Therefore, the volume distributions for the 194 distributions reported in Azimi et al. (2014) [29] are only accurate up to $\sim 2.5 \mu \mathrm{m}$. Thus, only the estimates of $\mathrm{PM}_{1}$ and $\mathrm{PM}_{2.5}$ concentrations (and $e \mathrm{PM}_{1}$ and $e \mathrm{PM}_{2.5}$ ) are accurate for these distributions (i.e., not the $\mathrm{PM}_{10}$ concentrations and $e \mathrm{PM}_{10}$ ). Moreover, it is also possible that the volume concentrations in the 1-2.5 $\mu \mathrm{m}$ size range estimated using the Azimi et al. (2014) [29] data are somewhat lower that reality, because most of the distributions measured via SMPS would miss some volume/mass estimates in that size range. However, this is likely a small issue, as most of the distributions still have substantial volume/mass in the $1-2.5 \mu \mathrm{m}$ size range.
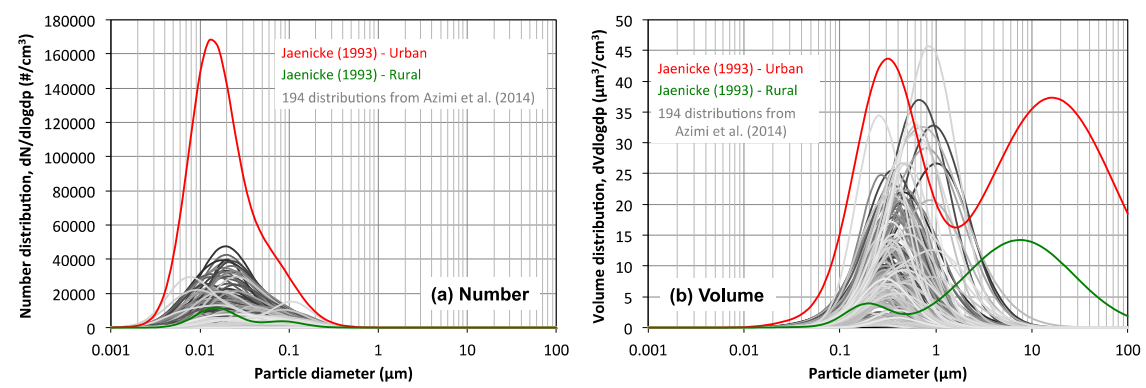

Figure 2. Trimodal (a) number and (b) volume distributions for 194 long-term outdoor particle size distributions across the world (from Azimi et al., 2014 [29]) overlaid with the urban and rural ambient distributions from Jaenicke (1993) [31].

To explore the impact of these assumptions for ambient aerosol distributions on resulting estimates of $e \mathrm{PM}$, Figure 3 shows estimates of $e \mathrm{PM}_{1}$ and $e \mathrm{PM}_{2.5}$ (but not $e \mathrm{PM}_{10}$ ) made for four HVAC filters that were originally tested for size-resolved removal efficiency in Hecker and Hofacre (2008) (rated at MERV 6, 8, 10, and 14, as shown in Figure 4) [35], assuming the filtration of $100 \%$ outdoor air of (1) the ambient urban and rural volume distributions from Jaenicke (1993) [31], and (2) the average of the 194 ambient volume distributions from Azimi et al. (2014) [29].

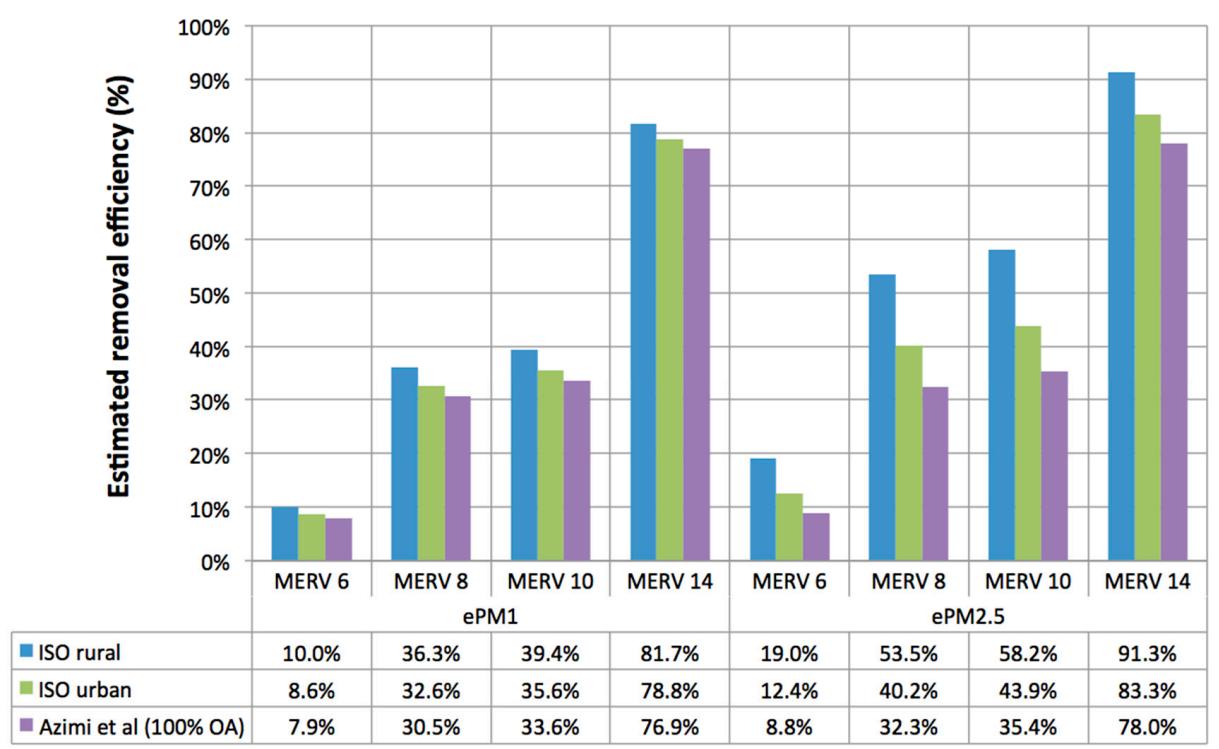

Figure 3. Estimates of $e \mathrm{PM}_{1}$ and $e \mathrm{PM}_{2.5}$ for four minimum efficiency reporting value (MERV)-rated filters from Hecker and Hofacre (2008) [35] made using the ambient urban and rural distributions from Jaenicke (1993) [31], and the average from using the 194 ambient distributions from Azimi et al. (2014) [29], assuming a filtration of $100 \%$ outdoor air. 


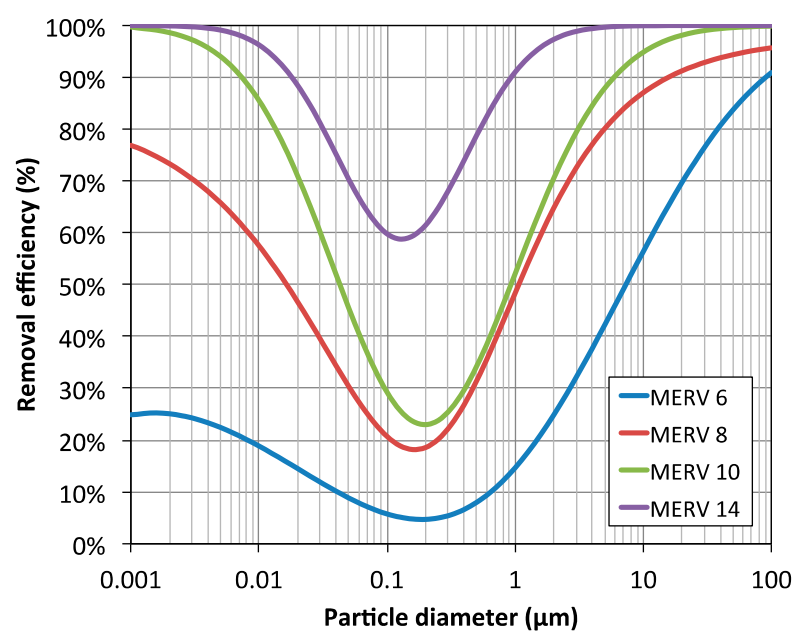

Figure 4. Size-resolved removal efficiency curves for four MERV-rated filters in Hecker and Hofacre (2008) [35].

Figure 3 demonstrates that the use of more modern ambient distributions yields different estimates of $e \mathrm{PM}$ than the ISO urban and rural distributions. Estimates of $e \mathrm{PM}_{2.5}$ had larger deviations than estimates of $e \mathrm{PM}_{1}$. Estimates of $e \mathrm{PM}_{1}$ deviated by $\sim 2-6 \%$ and $\sim 1-2 \%$ on an absolute basis between the Azimi et al. (2014) [29] distributions and the ISO rural and urban distributions, respectively. Conversely, estimates of $e \mathrm{PM}_{2.5}$ for the MERV 8 filter ranged from as low as $\sim 32 \%$ using the average of the ambient distributions from Azimi et al. (2014) to as high as $~ 54 \%$ using the rural distribution from ISO 16890; the urban distribution was in between these two estimates ( 40\%). Estimates for $e \mathrm{PM}_{2.5}$ for the MERV 6 filter ranged from $\sim 9 \%$ (Azimi et al.) to $\sim 12 \%$ (ISO urban) to $\sim 19 \%$ (ISO rural) [29]. The primary reason for these differences is that the peaks and overall shapes of the volume distributions in Figure 2 are reasonably well aligned for all of the distributions in the $<1 \mu \mathrm{m}$ size range, but not for the distributions in the $1-2.5 \mu \mathrm{m}$ size range.

\subsection{How Does the Outdoor-to-Indoor Transport of Ambient Aerosol Distributions Affect Estimates of ePM for Particles of Outdoor Origin?}

Indoor aerosols are most commonly a mixture of aerosols that transport from outdoors, and are emitted from indoor sources [41-43]. This section explores the impact of the outdoor-to-indoor transport of ambient aerosols alone (i.e., in the absence of indoor sources), while the subsequent section explores the impact of indoor distributions resulting from a combination of both indoor and outdoor sources.

As ambient aerosols transport indoors, they are subject to a number of size-dependent removal mechanisms that can alter the nature of the distributions, including penetration through the building envelope (if ambient aerosols are transported indoors via infiltration) and deposition to indoor surfaces [25,44]. Azimi et al. (2014) accounted for ambient particle penetration and deposition in typical residential buildings that rely mostly on infiltration for ventilation air to estimate $\mathrm{PM}_{2.5}$ and UFP removal efficiencies for indoor particles of outdoor origin (again, ignoring indoor sources) [29]. Although infiltration had a small effect on calculated removal efficiencies in that work, on average, some cases showed larger deviations than others.

Similarly, Figure 5 shows the absolute differences in estimates of $e \mathrm{PM}_{1}, e \mathrm{PM}_{2.5}$, and $e \mathrm{PM}_{10}$ that were made for the same ambient aerosol distributions in Figure 2, and the same four HVAC filters in Figure 4, although the ambient distributions were also modified to account for typical size-dependent residential infiltration factors. Differences were calculated as the estimated removal efficiency assuming that infiltration factors were applied prior to calculating $e \mathrm{PM}$ minus the removal efficiency estimated assuming the filtration of $100 \%$ outdoor air. These data are intended to provide a comparison of the 
two calculation approaches that are used for a given ambient distribution, which allows for comparing $\mathrm{PM}_{10}$ in addition to $\mathrm{PM}_{1}$ and $\mathrm{PM}_{2.5}$ for all three ambient distribution sources: ISO rural, ISO urban, and the average from the 194 distributions in Azimi et al. (2014) [29]. Assumptions for size-resolved infiltration factors based on typical size-resolved penetration factors, deposition loss rates, and air exchanges rates in US residences (from Azimi et al. 2014 [29]) are shown in Figure 6 [27]. Note that the literature on envelope penetration factors in commercial buildings is quite limited, so this analysis is only applicable for a typical US residential building that relies on infiltration alone. Moreover, this analysis ignores indoor sources, and thus the results are only applicable to periods of time in which indoor aerosols result only from the infiltration and persistence of ambient aerosols alone (i.e., indoor sources are ignored).

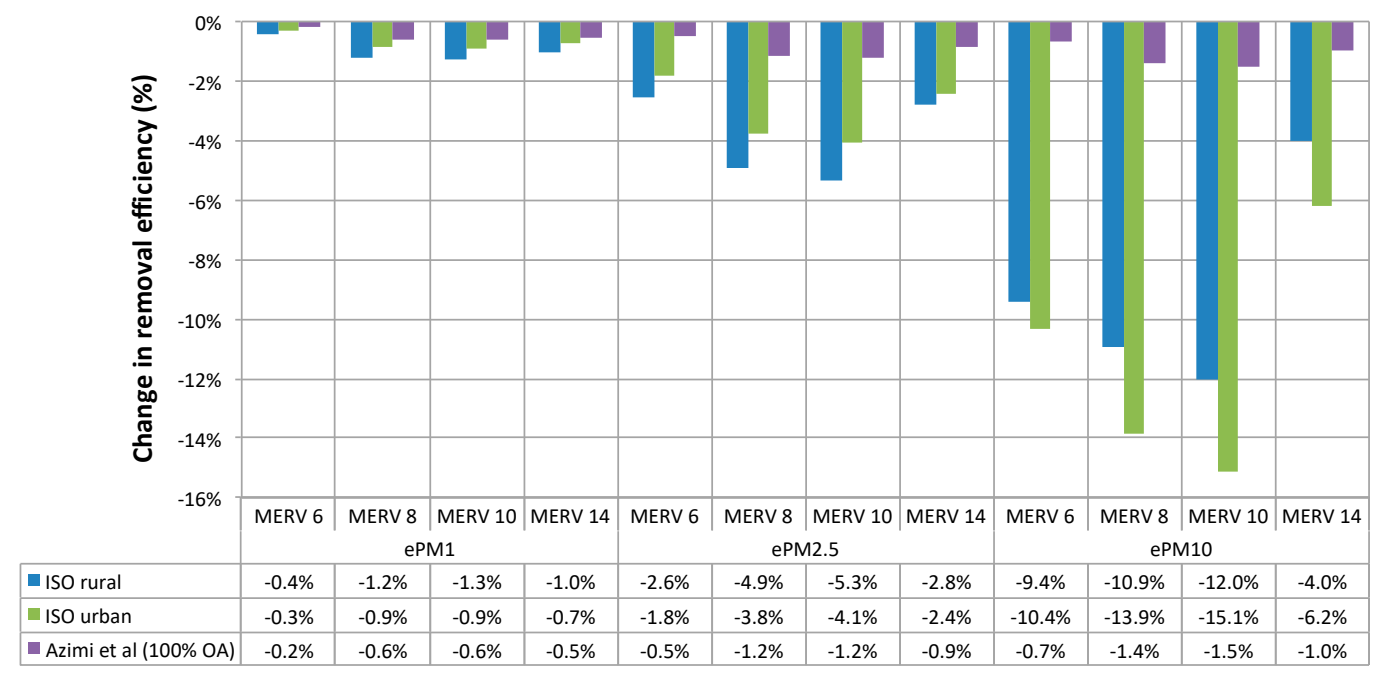

Figure 5. Absolute differences in estimates of $e \mathrm{PM}_{1}, e \mathrm{PM}_{2.5}$, and $e \mathrm{PM}_{10}$ for four MERV-rated filters made using various ambient size distributions and assuming that size-resolved infiltration factors are applied to account for the size-dependent aerosols transformations that occur in typical residential buildings in the absence of indoor sources. Values are calculated as the removal efficiency that is estimated assuming infiltration factors are first applied minus the removal efficiency estimated assuming the filtration of $100 \%$ outdoor air.

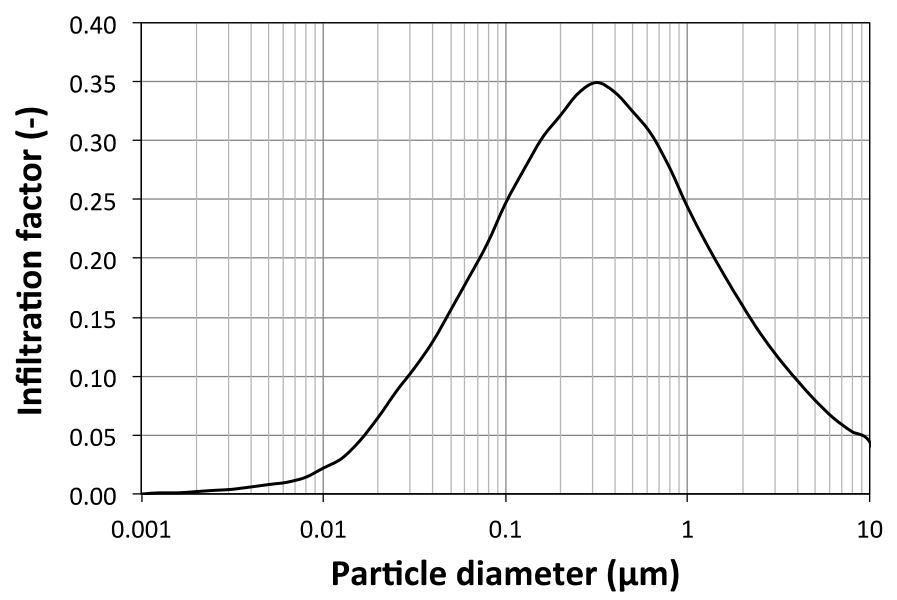

Figure 6. Size-resolved infiltration factors assumed in the analysis in Figure 5 [27,29].

Accounting for outdoor-to-indoor transformations had only a small influence on $e \mathrm{PM}_{1}$ for indoor particles of outdoor origin for all three assumed ambient aerosol distributions (i.e., less than $2 \%$ for all comparisons), but the magnitude of differences increased with increasing particle size classifications. 
This is particularly true for the urban and rural distributions used in ISO 16890, which show absolute deviations that are as high as $\sim 5 \%$ for $e \mathrm{PM}_{2.5}$, and as high as $\sim 15 \%$ for $e \mathrm{PM}_{10}$ for the MERV 8 and MERV 10 filters for indoor particles of outdoor origin. These high values are largely because a substantial portion of the ISO 16890 aerosol volume distributions is in the $1 \mu \mathrm{m}$ to $10 \mu \mathrm{m}$ size range. Particles greater than a few $\mu \mathrm{m}$ tend to have very low infiltration factors, due to both low penetration factors through building envelopes and high indoor deposition loss rates (Figure 6) [42,44]. This is a critical distinction to consider that, if not accounted for, can lead to rather large overestimations of $e \mathrm{PM}_{2.5}$ and $e \mathrm{PM}_{10}$ for indoor particles of outdoor origin if one uses only the $100 \%$ outdoor air assumptions in ISO 16890. It may be more appropriate to first account for transformations that occur during outdoor-to-indoor transport, rather than relying on $e$ PM reported according to ISO 18690, if one is to estimate $e$ PM removal efficiency of a filter for particles of outdoor origin for use in a building that relies on infiltration for ventilation air (which includes the vast majority of residences in the US, for example), as several studies have done recently [45-49]. It is also worth noting that the absolute differences in $e \mathrm{PM}_{2.5}$ and $e \mathrm{PM}_{10}$ were smaller for the MERV 14 filter, because the filter has a removal efficiency of almost $100 \%$ for particles larger than $3 \mu \mathrm{m}$, and over $90 \%$ for $1-3 \mu \mathrm{m}$ particles (Figure 4 ). Thus, the ambient transformations that most drastically affect the $>1 \mu \mathrm{m}$ size range (Figure 6 ) did not influence the $e \mathrm{PM}$ results as much as lower efficiency filters.

Table 2. Total number concentrations, geometric mean diameters, and geometric standard deviations for the trimodal residential indoor aerosol distributions fit to data reported in Abt et al. (2000) [50] and Long et al. (2001) [51].

\begin{tabular}{cccccccccc}
\hline \multirow{2}{*}{ Distribution } & \multicolumn{3}{c}{ Mode 1 } & \multicolumn{3}{c}{ Mode 2 } & \multicolumn{3}{c}{ Mode 3 } \\
\cline { 2 - 10 } & $N\left(\# / \mathrm{cm}^{3}\right)$ & $D_{g}(\mu \mathrm{m})$ & $\log \sigma_{g}$ & $N\left(\# / \mathrm{cm}^{3}\right)$ & $D_{g}(\mu \mathrm{m})$ & $\log \sigma_{g}$ & $N\left(\# / \mathrm{cm}^{3}\right)$ & $D_{g}(\mu \mathrm{m})$ & $\log \sigma_{g}$ \\
\hline Abt et al. (2000) & 10,700 & 0.065 & 0.280 & 3.5 & 0.8 & 0.180 & 0.4 & 1.5 & 0.280 \\
Long et al. (2001) & 6660 & 0.055 & 0.300 & 1 & 1 & 0.150 & 0.15 & 3.0 & 0.180 \\
\hline
\end{tabular}

\subsection{How Does the Use of Indoor Aerosol Distributions Affect Estimates of ePM?}

Since indoor aerosols most commonly result from a mixture of aerosols that are generated indoors and infiltrated from outdoors, estimates of $e \mathrm{PM}_{1}, e \mathrm{PM}_{2.5}$, and $e \mathrm{PM}_{10}$ were made for the same four HVAC filters, but assuming that the challenging aerosol was from a small sample of indoor aerosol distributions. Although there are no well-defined or standardized definitions of "typical" indoor aerosol distributions, the literature on indoor particle size and/or mass distributions was searched for those studies that used both an SMPS or similar instrument to measure sub-micrometer particles and an APS, OPS, or similar instrument to measure super-micrometer particles simultaneously. Two seminal studies of indoor aerosols distributions in a sample of US residences were found for use in this exploratory analysis: Abt et al. (2000) [50] and Long et al. (2001) [51]. Abt et al. (2000) [50] measured indoor and outdoor particle concentrations for approximately weeklong periods over multiple seasons in four single-family homes in Boston, Massachusetts, US, using a combined SMPS and APS sampling system to measure particles between $0.02-0.5 \mu \mathrm{m}$ and $0.07-10 \mu \mathrm{m}$, respectively. Long et al. (2001) [51] similarly measured indoor and outdoor concentrations for approximately weeklong periods over multiple seasons in nine single-family homes in Boston, Massachusetts, US using the same instrumentation as Abt et al. (2000) [50]. The average number and calculated volume concentrations throughout the entire sampling periods were reported in both studies, which captured the average of a variety of indoor aerosol sources including cooking, cleaning, resuspension from occupant activities, and infiltration from ambient air, among others.

Figure 7 shows the average indoor distributions from each study on a volume basis. The dashed lines represent the size-resolved data using the same size bins that were used in the original studies, and the solid lines represent manual approximations of trimodal logarithmic fits to these same distributions. Manual approximations of these distribution parameters are also shown in Table 2. 
Figure 8 also shows the same approximations of indoor volume distributions overlaid on top of the ambient distributions from Figure 2 for comparison purposes.

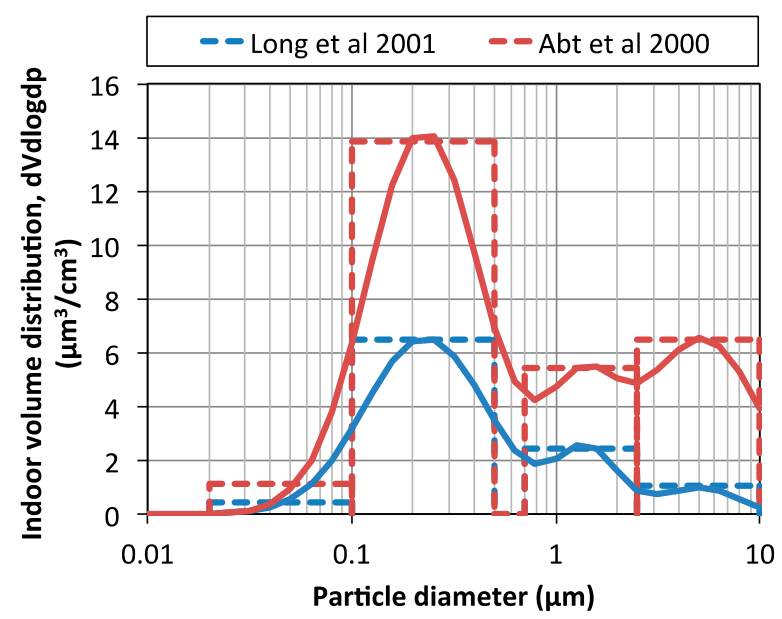

Figure 7. Residential indoor volume distributions for homes in Boston, Massachusetts (MA), in the United States (US) from Abt et al. (2000) [50] and Long et al. (2001) [51].

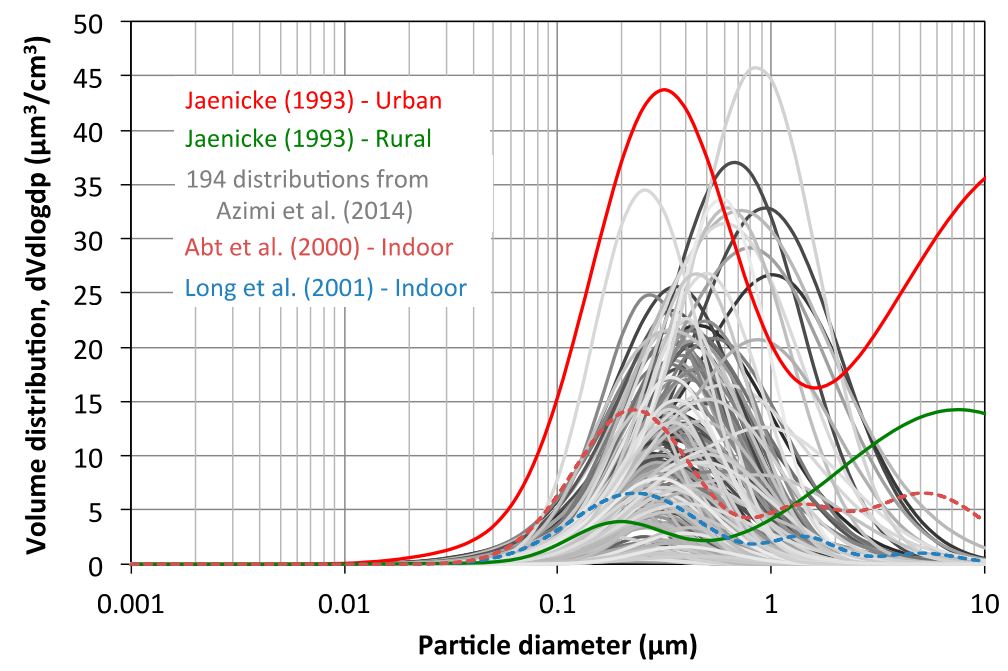

Figure 8. Residential indoor volume distributions for homes in Boston, MA, US from Abt et al. (2000) [50] and Long et al. (2001) [51], with the ambient distributions from Figure 2 overlaid.

There are some clear differences in the shape and magnitude of the ambient volume distributions from Jaenicke (1993) [31] (and ISO 16890), and the average indoor volume distributions from Abt et al. (2000) [50] and Long et al. (2001) [51]. For example, the peak volume concentration is $\sim 0.3 \mu \mathrm{m}$ for the urban ambient distribution, and $\sim 0.2 \mu \mathrm{m}$ for the indoor volume distributions. Additionally, the indoor distributions are relatively flat, from $\sim 1$ to $\sim 8 \mu \mathrm{m}$, while the ambient distributions vary widely in shape in the same size range. These differences are influenced by the nature of the underlying emission sources in the indoor studies, which can vary widely in the magnitude and shape of their number and volume distributions $[36,52,53]$.

Figure 9 shows estimates of $e \mathrm{PM}_{1}, e \mathrm{PM}_{2.5}$, and $e \mathrm{PM}_{10}$ for the same four HVAC filters that were used in prior sections made using (i) the ISO 16890 urban and rural ambient volume distributions (assuming filtration of $100 \%$ outdoor air) and (ii) the average indoor volume distributions from Abt et al. (2000) [50] and Long et al. (2001) [51]. The intent of this comparison is to demonstrate whether or not using the ambient distributions in ISO 16890 can be used to accurately estimate the $e$ PM for 
indoor aerosols. Although the number of indoor distributions is small, the comparison provides an exploratory analysis that could be further refined with additional indoor distribution data.

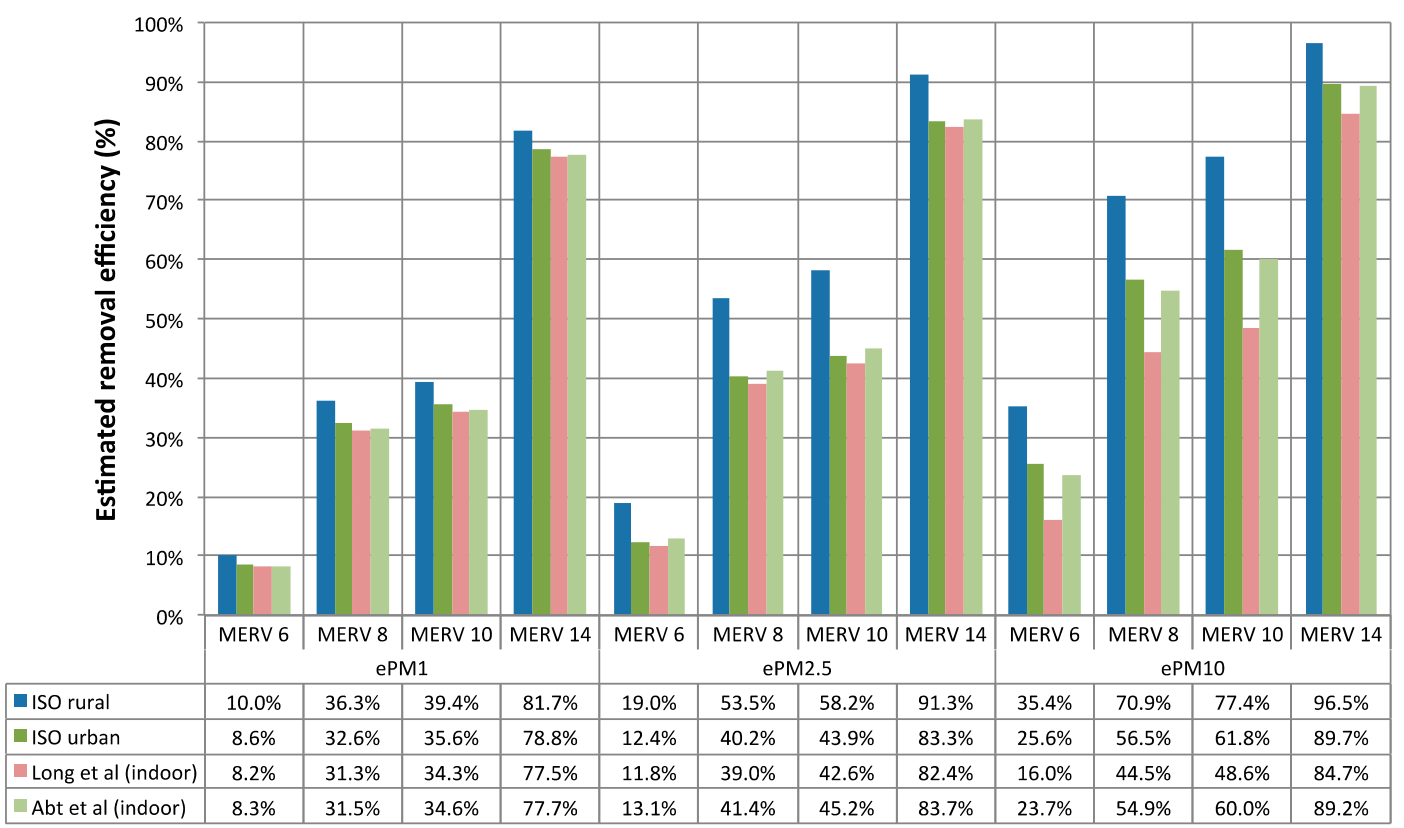

Figure 9. Estimates of $e \mathrm{PM}_{1}, e \mathrm{PM}_{2.5}$, and $e \mathrm{PM}_{10}$ for four HVAC filters made using the ISO 16890 ambient aerosol distributions (assuming filtration of 100\% outdoor air), and two indoor aerosol distributions for homes in Boston, MA, US from Abt et al. (2000) [50] and Long et al. (2001) [51].

The results in Figure 9 suggest that estimates of $e \mathrm{PM}$ made for ambient distributions following the current ISO 16890 standard cannot be used to accurately predict $e$ PM for all of the size classifications for use cases that involve recirculating HVAC systems with indoor sources, particularly for $e \mathrm{PM}_{10}$. For example, using the $100 \%$ outdoor air ISO urban and rural distributions resulted in estimates of $e \mathrm{PM}_{10}$ for the MERV 6 filter of $25.6 \%$ and 35.4\%, respectively. Meanwhile, using the Abt et al. (2000) [50] and Long et al. (2001) [51] indoor distributions resulted in estimates of $\sim 24 \%$ and $\sim 16 \%$, respectively. Even more drastically, using the 100\% outdoor air ISO urban and rural distributions resulted in estimates of $e \mathrm{PM}_{10}$ for the MERV 10 filter of $\sim 62 \%$ and $\sim 77 \%$, respectively, while using the Abt et al. (2000) [50] and Long et al. (2001) [51] indoor distributions resulted in estimates of $\sim 60 \%$ and $\sim 49 \%$, respectively. Interestingly, the estimates of $e \mathrm{PM}_{1}$ and $e \mathrm{PM}_{2.5}$ for all four filters were reasonably similar for the two indoor aerosol distributions and the ISO urban ambient distribution (i.e., within $2 \%$ or less for all of the comparisons), suggesting that the approach in ISO 16890 may yield reasonable estimates for typical indoor residential applications, although further investigation with greater numbers of indoor distributions is warranted.

\section{Discussion}

This work demonstrates the following key findings:

1. The urban and rural ambient aerosol distributions used in ISO 16890 date back to the 1970s, and have number concentrations that greatly exceed most recent ambient aerosol distributions. However, the shape of the number distributions are somewhat similar to more recent ambient distributions, albeit with some deviations in the $\sim 0.05-0.5 \mu \mathrm{m}$ size range.

2. Differences in estimates of $e \mathrm{PM}$ for filtration of $100 \%$ outdoor air made using the historical ambient aerosol distributions in ISO 16890 and more modern ambient distributions can be substantial (particularly for $e \mathrm{PM}_{2.5}$ ). 
3. Failing to account for size-resolved transformations that typically occur during outdoor-to-indoor transport, particularly in residential buildings, yields estimates of $e \mathrm{PM}$ for indoor particles of outdoor origin that are overestimated by as much as $\sim 15 \%$ (on a relative basis) for the four HVAC filters investigated herein.

4. The use of indoor aerosol distributions to represent indoor particulate matter that is a mixture of indoor and outdoor sources rather than assuming filtration of $100 \%$ outdoor air yields relatively large differences in estimates of $e \mathrm{PM}_{10}$, but estimates of $e \mathrm{PM}_{1}$ and $e \mathrm{PM}_{2.5}$ were actually quite similar.

Overall, these results demonstrate that, with some exceptions, the assumption that one uses for aerosol number and volume distributions can have a large impact on the resulting estimates of $e \mathrm{PM}_{1}$, $e \mathrm{PM}_{2.5}$, and $e \mathrm{PM}_{10}$. Moreover, these results lead to the following recommendations for improving ISO 16890 and other test standards that attempt to incorporate estimates mass-based particle removal efficiency:

1. The historical and static ambient aerosol distributions should be updated to reflect more modern ambient environments.

2. The standard should reconsider its use of the somewhat artificial distinction that filters that were designed to filter primarily $\mathrm{PM}_{1}$ and $\mathrm{PM}_{2.5}$ size fractions be characterized using only the urban aerosol distribution, and that filters designed to filter primarily $\mathrm{PM}_{10}$ be characterized using only on the rural volume distribution. Given that HVAC filters are currently marketed and sold to consumers without the distinction of whether the filter should be used in an urban or rural environment, and that suburban and other environments are not explicitly addressed, this practice will likely lead to more confusion than clarity.

3. The standard should be modified in order to allow for estimations of $e \mathrm{PM}$ based on other commonly used HVAC system configurations in addition to $100 \%$ outdoor, including $100 \%$ recirculation systems, and mixed outdoor/recirculation systems with variable outdoor air fractions in which indoor PM is a mixture of aerosols that are generated indoors and transported from outdoors (often through building envelopes, particularly in residences, but not always).

4. To support item \#3 above, further research should be conducted in order to more robustly characterize indoor aerosol distributions in a wide variety of building types and under a variety of conditions (e.g., varying emission sources, ventilation rates, etc.).

5. Although not explicitly address herein, the vast majority of particles in both indoor and outdoor environments (on a number basis) are typically smaller than $0.3 \mu \mathrm{m}$ (and typically ultrafine particles, or UFPs, smaller than $0.1 \mu \mathrm{m}$ ) [36,54,55]. Therefore, ISO 16890 and other standards should consider adopting measures of removal efficiency for size-resolved and/or total UFPs to better characterize the impact that filters can have on IAQ.

\section{Conclusions}

This work investigated the sensitivity of the mass-based removal efficiency calculation procedures that are described in ISO 16890 to various assumptions for aerosol distributions. The results demonstrate that knowing the PM mass removal efficiency based only on the method that is described in ISO 16890 is not sufficient for predicting the PM mass removal efficiency in all of the environments in which the filter might be used, albeit with some exceptions. This limitation is primarily because assumptions regarding the aerosol number and volume distribution can greatly impact the calculation results, albeit with some fortunate exceptions. Further work is recommended to revise the method to account for alternative aerosol distributions that may more realistically represent a greater number of building applications.

Acknowledgments: This work was funded in part by Kimberly-Clark through a subcontract with ZENE, LLC and in part by an ASHRAE New Investigator Award. Thanks to Jim Rosenthal for providing the inspiration for this analysis and for providing a careful review of a draft of this report. 
Conflicts of Interest: The author declares no conflict of interest. The founding sponsors had no role in the design of the study; in the analysis or interpretation of data; in the writing of the manuscript, and in the decision to publish the results.

\section{References}

1. Stephens, B.; Brennan, T.; Harriman, L. Selecting ventilation air filters to reduce $\mathrm{PM}_{2.5}$ of outdoor origin. ASHRAE J. 2016, 9, 12-20.

2. Singer, B.C.; Delp, W.W.; Black, D.R.; Walker, I.S. Measured performance of filtration and ventilation systems for fine and ultrafine particles and ozone in an unoccupied modern California house. Indoor Air 2016, 27, 780-790. [CrossRef] [PubMed]

3. Chan, W.R.; Parthasarathy, S.; Fisk, W.J.; McKone, T.E. Estimated effect of ventilation and filtration on chronic health risks in U.S. offices, schools, and retail stores. Indoor Air 2016, 26, 331-343. [CrossRef] [PubMed]

4. McCarthy, M.C.; Ludwig, J.F.; Brown, S.G.; Vaughn, D.L.; Roberts, P.T. Filtration effectiveness of HVAC systems at near-roadway schools. Indoor Air 2013, 23, 196-207. [CrossRef] [PubMed]

5. Polidori, A.; Fine, P.M.; White, V.; Kwon, P.S. Pilot study of high-performance air filtration for classroom applications. Indoor Air 2013, 23, 185-195. [CrossRef] [PubMed]

6. MacIntosh, D.L.; Minegishi, T.; Kaufman, M.; Baker, B.J.; Allen, J.G.; Levy, J.I.; Myatt, T.A. The benefits of whole-house in-duct air cleaning in reducing exposures to fine particulate matter of outdoor origin: A modeling analysis. J. Expo. Sci. Environ. Epidemiol. 2010, 20, 213-224. [CrossRef] [PubMed]

7. Brown, K.W.; Minegishi, T.; Allen, J.; McCarthy, J.F.; Spengler, J.D.; MacIntosh, D.L. Reducing Patients' Exposures to Asthma and Allergy Triggers in their Homes: An Evaluation of Effectiveness of Grades of Forced Air Ventilation Filters. J. Asthma 2014, 51, 585-594. [CrossRef] [PubMed]

8. ASHRAE Standard 52.2: Method of Testing General Ventilation Air-Cleaning Devices for Removal Efficiency by Particle Size; ASHRAE: Atlanta, GA, USA, 2017.

9. ISO 16890: Air Filters for General Ventilation 2016; ISO: Geneva, Switzerland, 2016.

10. Brook, R.D.; Rajagopalan, S.; Pope, C.A.; Brook, J.R.; Bhatnagar, A.; Diez-Roux, A.V.; Holguin, F.; Hong, Y.; Luepker, R.V.; Mittleman, M.A.; et al. Particulate matter air pollution and cardiovascular disease. Circulation 2010, 121, 2331-2378. [CrossRef] [PubMed]

11. Di, Q.; Wang, Y.; Zanobetti, A.; Wang, Y.; Koutrakis, P.; Choirat, C.; Dominici, F.; Schwartz, J.D. Air Pollution and Mortality in the Medicare Population. N. Engl. J. Med. 2017, 376, 2513-2522. [CrossRef] [PubMed]

12. Dockery, D.W.; Pope, C.A., 3rd; Xu, X.; Spengler, J.D.; Ware, J.H.; Fay, M.E.; Ferris, B.G., Jr.; Speizer, F.E. An association between air pollution and mortality in six U.S. cities. N. Engl. J. Med. 1993, 329, 1753-1759. [CrossRef] [PubMed]

13. Gharibvand, L.; Shavlik, D.; Ghamsary, M.; Beeson, W.L.; Soret, S.; Knutsen, R.; Knutsen, S.F. The Association between Ambient Fine Particulate Air Pollution and Lung Cancer Incidence: Results from the AHSMOG-2 Study. Environ. Health Perspect. 2017, 125, 378-384. [CrossRef] [PubMed]

14. Krewski, D.; Jerrett, M.; Burnett, R.T.; Ma, R.; Hughes, E.; Shi, Y.; Turner, M.C.; Pope, C.A., III; Thurston, G.; Calle, E.E.; et al. Extended follow-up and spatial analysis of the American Cancer Society study linking particulate air pollution and mortality. Res. Rep. Health Eff. Inst. 2009, 140, 5-114.

15. Pope, C.A.; Burnett, R.T.; Thun, M.J.; Calle, E.E.; Krewski, D.; Ito, K.; Thurston, G.D. Lung cancer, cardiopulmonary mortality, and long-term exposure to fine particulate air pollution. JAMA J. Am. Med. Assoc. 2002, 287, 1132-1141. [CrossRef]

16. Pope, C.A.; Dockery, D.W. Health effects of fine particulate air pollution: Lines that connect. J. Air Waste Manag. Assoc. 2006, 56, 709-742. [CrossRef] [PubMed]

17. Shi, L.; Zanobetti, A.; Kloog, I.; Coull, B.A.; Koutrakis, P.; Melly, S.J.; Schwartz, J.D. Low-Concentration PM 2.5 and Mortality: Estimating Acute and Chronic Effects in a Population-Based Study. Environ. Health Perspect. 2015, 124, 46-52. [CrossRef] [PubMed]

18. U.S. Environmental Protection Agency. Integrated Science Assessment for Particulate Matter; U.S. EPA: Washington, DC, USA, 2009.

19. Logue, J.M.; Price, P.N.; Sherman, M.H.; Singer, B.C. A method to estimate the chronic health impact of air pollutants in U.S. residences. Environ. Health Perspect. 2012, 120, 216-222. [CrossRef] [PubMed] 
20. McDonnell, W.F.; Nishino-Ishikawa, N.; Petersen, F.F.; Chen, L.H.; Abbey, D.E. Relationships of mortality with the fine and coarse fractions of long-term ambient $\mathrm{PM}_{10}$ concentrations in nonsmokers. J. Expo. Sci. Environ. Epidemiol. 2000, 10, 427-436. [CrossRef]

21. CEN EN 779: Particulate Air Filters for General Ventilation-Determination of the Filtration Performance; European Committee for Standardization: Brussels, Belgium, 2012.

22. Neusüss, C.; Wex, H.; Birmili, W.; Wiedensohler, A.; Koziar, C.; Busch, B.; Brüggemann, E.; Gnauk, T.; Ebert, M.; Covert, D.S. Characterization and parameterization of atmospheric particle number-, mass-, and chemical-size distributions in central Europe during LACE 98 and MINT. J. Geophys. Res. 2002, 107, LAC 91-LAC 913. [CrossRef]

23. Pitz, M.; Schmid, O.; Heinrich, J.; Birmili, W.; Maguhn, J.; Zimmermann, R.; Wichmann, H.-E.; Peters, A.; Cyrys, J. Seasonal and Diurnal Variation of $\mathrm{PM}_{2.5}$ Apparent Particle Density in Urban Air in Augsburg, Germany. Environ. Sci. Technol. 2008, 42, 5087-5093. [CrossRef] [PubMed]

24. Hu, M.; Peng, J.; Sun, K.; Yue, D.; Guo, S.; Wiedensohler, A.; Wu, Z. Estimation of Size-Resolved Ambient Particle Density Based on the Measurement of Aerosol Number, Mass, and Chemical Size Distributions in the Winter in Beijing. Environ. Sci. Technol. 2012, 46, 9941-9947. [CrossRef] [PubMed]

25. Riley, W.J.; McKone, T.E.; Lai, A.C.K.; Nazaroff, W.W. Indoor particulate matter of outdoor origin: Importance of size-dependent removal mechanisms. Environ. Sci. Technol. 2002, 36, 200-207. [CrossRef] [PubMed]

26. Waring, M.S.; Siegel, J.A. Particle loading rates for HVAC filters, heat exchangers, and ducts. Indoor Air 2008, 18, 209-224. [CrossRef] [PubMed]

27. El Orch, Z.; Stephens, B.; Waring, M.S. Predictions and determinants of size-resolved particle infiltration factors in single-family homes in the U.S. Build. Environ. 2014, 74, 106-118. [CrossRef]

28. Zaatari, M.; Novoselac, A.; Siegel, J. The relationship between filter pressure drop, indoor air quality, and energy consumption in rooftop HVAC units. Build. Environ. 2014, 73, 151-161. [CrossRef]

29. Azimi, P.; Zhao, D.; Stephens, B. Estimates of HVAC filtration efficiency for fine and ultrafine particles of outdoor origin. Atmos. Environ. 2014, 98, 337-346. [CrossRef]

30. Seinfeld, J.H.; Pandis, S.N. Atmospheric Chemistry and Physics: From Air Pollution to Climate Change, 2nd ed.; Wiley-Interscience: Hoboken, NJ, USA, 2006.

31. Jaenicke, R. Chapter 1 Tropospheric Aerosols. In International Geophysics; Elsevier: San Diego, CA, USA, 1993; Volume 54, pp. 1-31.

32. Hobbs, P.V.; Bowdle, D.A.; Radke, L.F. Particles in the Lower Troposphere over the High Plains of the United States. Part I: Size Distributions, Elemental Compositions and Morphologies. J. Clim. Appl. Meteorol. 1985, 24, 1344-1356. [CrossRef]

33. Jaenicke, R.; Junge, C. Studien zur oberen Grenzgröße des natürlichen Aerosols. Beitr. Phys. Atmos. 1967, 40, 129-142. (In German)

34. Whitby, K.T. The physical characteristics of sulfur aerosols. Atmos. Environ. 1978, 12, 135-159. [CrossRef]

35. Hecker, R.; Hofacre, K.C. Development of Performance Data for Common Building Air Cleaning Devices; U.S. Environmental Protection Agency: Washington, DC, USA, 2008.

36. Wallace, L. Indoor sources of ultrafine and accumulation mode particles: Size distributions, size-resolved concentrations, and source strengths. Aerosol Sci. Technol. 2006, 40, 348-360. [CrossRef]

37. Kearney, J.; Wallace, L.; MacNeill, M.; Xu, X.; VanRyswyk, K.; You, H.; Kulka, R.; Wheeler, A.J. Residential indoor and outdoor ultrafine particles in Windsor, Ontario. Atmos. Environ. 2010. [CrossRef]

38. Chan, W.R.; Logue, J.M.; Wu, X.; Klepeis, N.E.; Fisk, W.J.; Noris, F.; Singer, B.C. Quantifying fine particle emission events from time-resolved measurements: Method description and application to 18 California low-income apartments. Indoor Air 2017, 28, 89-101. [CrossRef] [PubMed]

39. MacNeill, M.; Kearney, J.; Wallace, L.; Gibson, M.; Héroux, M.E.; Kuchta, J.; Guernsey, J.R.; Wheeler, A.J. Quantifying the contribution of ambient and indoor-generated fine particles to indoor air in residential environments. Indoor Air 2014, 24, 362-375. [CrossRef] [PubMed]

40. Morawska, L.; Afshari, A.; Bae, G.N.; Buonanno, G.; Chao, C.Y.H.; Hänninen, O.; Hofmann, W.; Isaxon, C.; Jayaratne, E.R.; Pasanen, P.; et al. Indoor aerosols: From personal exposure to risk assessment. Indoor Air 2013, 23, 462-487. [CrossRef] [PubMed]

41. Allen, R.W.; Adar, S.D.; Avol, E.; Cohen, M.; Curl, C.L.; Larson, T.; Liu, L.-J.S.; Sheppard, L.; Kaufman, J.D. Modeling the residential infiltration of outdoor $\mathrm{PM}_{2.5}$ in the Multi-Ethnic Study of Atherosclerosis and Air Pollution (MESA Air). Environ. Health Perspect. 2012, 120, 824-830. [CrossRef] [PubMed] 
42. Chen, C.; Zhao, B. Review of relationship between indoor and outdoor particles: I/O ratio, infiltration factor and penetration factor. Atmos. Environ. 2011, 45, 275-288. [CrossRef]

43. Meng, Q.Y.; Turpin, B.J.; Korn, L.; Weisel, C.P.; Morandi, M.; Colome, S.; Zhang, J.; Stock, T.; Spektor, D.; Winer, A.; et al. Influence of ambient (outdoor) sources on residential indoor and personal $\mathrm{PM}_{2.5}$ concentrations: Analyses of RIOPA data. J. Expo. Anal. Environ. Epidemiol. 2005, 15, 17-28. [CrossRef] [PubMed]

44. Nazaroff, W.W. Indoor particle dynamics. Indoor Air 2004, 14, 175-183. [CrossRef] [PubMed]

45. Zhao, D.; Azimi, P.; Stephens, B. Evaluating the long-term health and economic impacts of central residential air filtration for reducing premature mortality associated with indoor fine particulate matter $\left(\mathrm{PM}_{2.5}\right)$ of outdoor origin. Int. J. Environ. Res. Public Health 2015, 12, 8448-8479. [CrossRef] [PubMed]

46. Azimi, P.; Zhao, D.; Stephens, B. Modeling the Impact of Residential HVAC Filtration on Indoor Particles of Outdoor Origin (RP-1691). Sci. Technol. Built Environ. 2016, 22, 431-462. [CrossRef]

47. Montgomery, J.F.; Reynolds, C.C.O.; Rogak, S.N.; Green, S.I. Financial implications of modifications to building filtration systems. Build. Environ. 2015, 85, 17-28. [CrossRef]

48. Bekö, G.; Clausen, G.; Weschler, C. Is the use of particle air filtration justified? Costs and benefits of filtration with regard to health effects, building cleaning and occupant productivity. Build. Environ. 2008, 43, 1647-1657. [CrossRef]

49. Fisk, W.J.; Chan, W.R. Effectiveness and cost of reducing particle-related mortality with particle filtration. Indoor Air 2017, 27, 909-920. [CrossRef] [PubMed]

50. Abt, E.; Suh, H.H.; Allen, G.; Koutrakis, P. Characterization of indoor particle sources: A study conducted in the metropolitan Boston area. Environ. Health Perspect. 2000, 108, 35-44. [CrossRef] [PubMed]

51. Long, C.M.; Suh, H.H.; Catalano, P.J.; Koutrakis, P. Using time- and size-resolved particulate data to quantify indoor penetration and deposition behavior. Environ. Sci. Technol. 2001, 35, 2089-2099. [CrossRef] [PubMed]

52. Hussein, T.; Glytsos, T.; Ondracek, J.; Dohanyosova, P.; Zdimal, V.; Hameri, K.; Lazaridis, M.; Smolik, J.; Kulmala, M. Particle size characterization and emission rates during indoor activities in a house. Atmos. Environ. 2006, 40, 4285-4307. [CrossRef]

53. Afshari, A.; Matson, U.; Ekberg, L.E. Characterization of indoor sources of fine and ultrafine particles: A study conducted in a full-scale chamber. Indoor Air 2005, 15, 141-150. [CrossRef] [PubMed]

54. Wallace, L.; Ott, W. Personal exposure to ultrafine particles. J. Expo. Sci. Environ. Epidemiol. 2011, 21, 20-30. [CrossRef] [PubMed]

55. Health Effects Institute. Understanding the Health Effects of Ambient Ultrafine Particles; Health Effects Institute: Boston, MA, USA, 2013. 